\section{In Reply to Dr Connors et al}

To the Editor:

We are very grateful to read the comments from Connors et $\mathrm{al}^{1}$ on our article. ${ }^{2}$ Amatoxin poisoning is a medical emergency characterized by hepatoxicity, encephalopathy, coma, and death. The main amatoxins are $\alpha, \beta$, and $\gamma$ amanitins. They inhibit eukaryotic RNA polymerase II, causing transcriptional arrest and affecting metabolically highly active cells such as hepatocytes and kidney cells. Amanita toxin has a molecular weight of 373 to $990 \mathrm{Da}$, is

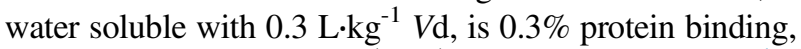
and has 2.7 to $6.2 \mathrm{~mL} \cdot \mathrm{min}^{-1} \cdot \mathrm{kg}^{-1}$ endogenous clearance. ${ }^{1}$

Although oral decontamination with activated charcoal, intravenous hydration, $\mathrm{N}$-acetyl cysteine, silibinin, and penicillin are recommended in the standard treatment approach, these treatments are often insufficient because symptoms occur after a relatively long and obscure incubation period. Extracorporeal treatments (eg, conventional hemodialysis [HD], continuous renal replacement therapies [CRRT], plasmapheresis, hemoperfusion [HP], extracorporeal albumin dialysis) can be used to remove toxic compounds from the body for supportive treatment in clinical emergency situations when specific treatment is insufficient. ${ }^{3,4}$ The lack of well-designed studies on the optimal method of extracorporeal removal of toxic compounds, thus staying at a lower level of evidence, is a major problem.

The more expeditiously toxins are removed, the less chance major toxicity will ensue ${ }^{5}$; thus, extracorporeal treatment may be an efficacious alternative treatment modality. In general, clearance of dialysable substances is lower with CRRT than with conventional $\mathrm{HD}^{6}$ owing to slower flow rates, and although HD is readily available in most hospitals, many are not capable of delivering CRRT, HP, plasmapheresis, or extracorporeal albumin dialysis. One of the problems with toxin removal by dialyzers and HP devices is that their effects on pharmacokinetic parameters other than simple clearance measurements are largely unknown. This problem can also be experienced in newly developed dialyzers (midcutoff, high-cutoff). However, new studies can be instructive.

Owing to the urgent nature of amatoxin poisoning treatment and uncertainties in resolving potential complications, we may never be able to find well-designed, evidence-based studies to guide us. In dealing with these controversial issues, we must continue to use less than ideal evidence and our own experience to guide our decision-making.

\author{
Mugla University \\ Mugla, Turkey \\ İsmail Kırlı, Assist. Prof. Dr. \\ Mehmet Yılmaz, MD \\ Aytuğ Çağırtekin, MD \\ Department of Internal Medicine \\ Faculty of Medicine \\ Mugla University \\ Mugla, Turkey \\ Hakan Allı, Assoc. Prof. Dr. \\ Department of Biology \\ Faculty of Science and Arts \\ Mugla University \\ Mugla, Turkey \\ Sultan Edebali, MD \\ Department of Internal Medicine \\ Faculty of Medicine \\ Mugla University \\ Mugla, Turkey
}

\section{References}

1. Connors NJ, Gosselin S, Hoffman RS. Regarding "Median cut-off membrane can be a new treatment tool in Amanita phalloides poisoning." Wilderness Environ Med. 2021;32(4): 554.

2. Huddam B, Alp A, Kırlı I, Yılmaz M, Çă̆ırtekin A, Allı H, et al. Medium cut-off membrane can be a new treatment tool in Amanita phalloides poisoning. Wilderness Environ Med. 2021;32(2):192-7.

3. Goldfarb DS. Principles and techniques applied to enhance the elimination of toxic compounds. In: Goldfrank LR, Smith SW, Lewin NA, Howland MA, Hoffman RS, Nelson LS, eds. Goldfrank's Toxicologic Emergencies. 11th ed. New York: McGraw-Hill; 2019:90-101.

4. Ye Y, Liu Z. Management of Amanita phalloides poisoning: a literature review and update. J Crit Care. 2018;46:17-22.

5. King JD, Kern MH, Jaar BG. Extracorporeal removal of poisons and toxins. Clin J Am Soc Nephrol. 2019;14(9):1408-15.

6. Sigler MH, Teehan BP, Daugirdas JT, Ing TS. Slow continuous therapies. In: Daugirdas JT, Blake PG, Ing TS, eds., Handbook of Dialysis. 3rd ed. Philadelphia: Lippincott Williams \& Wilkins, 2001:199-230.

\section{More or Less? Wilderness Education in Emergency Medicine Residencies}

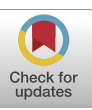

Bülent Huddam, Prof. Dr. Alper Alp, Assist. Prof. Dr. Department of Nephrology Faculty of Medicine
To the Editor:

In "A National Survey of Wilderness Medicine Curricula in United States Emergency Medicine 
Residencies," the authors state that $63 \%$ of emergency medicine (EM) residencies that responded to their survey had some form of wilderness medicine (WM) training as part of their residency curriculum. ${ }^{1}$ Yet, the data they put forth are less than convincing that this is an accurate assessment. Using data from a survey in which only $57 \%$ (136 of 240) of EM programs responded is an unreliable surrogate for what the reality of national WM education entails. The authors did address this as a limitation, stating that if the 104 nonresponding programs were assumed not to offer any WM education, then only $35 \%$ of programs would. Although we applaud their selfawareness relating to this flaw of the study, 35\% compared to $63 \%$ is a massive difference that changes the conversation from most to few programs teaching WM.

It is unclear from the article whether the authors were attempting to determine WM education within or outside the educational recommendations set forth by the Core Content Task Force II. In 2016, that group published an updated Model of the Clinical Practice of Emergency Medicine, which outlines the topics necessary for a complete resident education. ${ }^{2}$ (Of note, a more recent model was published in 2019, but this would not have been available to the study authors at the time of their survey. ${ }^{3}$ ) In that model, topics such as high altitude illness and decompression syndrome are listed under "environmental disorders," but they easily qualify as WM content. ${ }^{4}$ With this in mind, every program should be teaching WM to a degree. Any program stating that it does not may be unaware that it does or may have interpreted the opening survey question ("Does your program teach WM?") as meaning teaching WM other than what is listed in the core content. Depending on the authors' true intent, this could lead to either a huge underreporting or overreporting of WM education.

It should also be noted that a similar study was undertaken only 3 y earlier, which in itself makes us question the utility of this updated study given that only a short time has passed. The authors in that study, however, attempted to parse the difference between required and optional WM education activities within EM residencies. ${ }^{5}$ The most recent study did not, and that failure adds to the confusion surrounding the data and interpretation of the results. For example, at our institution we offer our residents additional training in tactical and combat medicine, but we would never say that we teach tactical or combat medicine as part of our residency curriculum.

The authors also chose not to include or analyze data related to the geographic location of the responding institutions. In the presence of a $56 \%$ response rate, performing a subanalysis of the geographic locations of respondents would go a long way to support the data being a true representation of the national WM curricula. Seeing as 144 of the 240 EM residencies at the time of the survey were located in the Northeast, Southeast, or Midwest, if all 136 responders were from these regions, it would obviously not be a true national representation. ${ }^{6}$ In this hypothetical scenario, the entire West, Southwest, and Northwest would have been absent.

Although a regular assessment of EM residency WM education is useful, this particular study does little to expand our insight. We openly acknowledge that getting high survey return rates is very difficult and respect the authors' attempts while acknowledging their own study's limitations. Unfortunately, the low return rates and vagueness of the study's intent leaves us with more questions than answers. In the future, however, the lessons learned from this study can potentially aid the subspecialty in truly assessing WM educational offerings within EM residencies.

Adam D. Hill, MD

Section of Wilderness and Environmental Medicine Department of Emergency Medicine Icahn School of Medicine at Mount Sinai New York, New York

\section{References}

1. Goldflam K, Coughlin RF, Cotton Widdicombe A, DellaGiustina D. A national survey of wilderness medicine curricula in United States emergency medicine residencies. Wilderness Environ Med. 2021;32(2):187-91.

2. Counselman FL, Babu K, Edens MA, Gorgas DL, Hobgood C, Marco CA, et al. The 2016 model of the clinical practice of emergency medicine. J Emerg Med. 2017;52(6):846-9.

3. Beeson MS, Ankel F, Bhat R, Broder JS, Dimeo SP, Gorgas DL, et al. The 2019 model of the clinical practice of emergency medicine. J Emerg Med. 2020;59(1):96-120.

4. Schrading WA, Battaglioli N, Drew J, McClure SF. Core content for wilderness medicine training: development of a wilderness medicine track within an emergency medicine residency. Wilderness Environ Med. 2018;29(1):78-84.

5. Aronstam EJ, Christensen ML, Williams MP, Overton DT. Wilderness medicine curricular content in emergency medicine residency programs. Wilderness Environ Med. 2015;26(4):577-9.

6. Society for Academic Emergency Medicine. Residency Directory. Available at: https://member.saem.org/SAEMIMIS/ SAEM_Directories/ResidencyMap/SAEM_Directories/P/ ResidencyMap.aspx?hkey=1e134970-ec57-4862-87fb-6971bad 7a77b. Accessed July 2, 2021. 